\title{
Analysis of human urine metabolites using SPE and NMR spectroscopy
}

\author{
YANG WeiJin ${ }^{1 \dagger}$, WANG YaWei ${ }^{1}$, ZHOU QunFang $^{1}$ \& TANG HuiRu ${ }^{2 \dagger}$ \\ ${ }^{1}$ State Key Laboratory of Environmental Chemistry and Ecotoxicology, Research Center for Eco-Environmental Sciences, Chinese \\ Academy of Sciences, Beijing 100085, China; \\ ${ }^{2}$ State Key Laboratory of Magnetic Resonance and Atomic and Molecular Physics, Wuhan Centre for Magnetic Resonance, Wuhan \\ Institute of Physics and Mathematics, Chinese Academy of Sciences, Wuhan 430071, China
}

\begin{abstract}
Nuclear magnetic resonance (NMR) spectroscopic analysis of metabonome/metabolome has widespread applications in biomedical science researches. However, most of NMR resonances for urinary metabolites remain to be fully assigned. In the present study, human urine samples from two healthy volunteers were pre-treated with $\mathrm{C} 18$ solid-phase extraction and the resultant 5 sub-fractions were subjected to one- and two-dimensional NMR studies, including ${ }^{1} \mathrm{H}$ J-Resolved, ${ }^{1} \mathrm{H}-{ }^{1} \mathrm{H}$ COSY, ${ }^{1} \mathrm{H}-{ }^{1} \mathrm{H}$ TOCSY, ${ }^{1} \mathrm{H}-{ }^{13} \mathrm{C}$ HSQC, and HMBC 2D NMR. More than 70 low molecular weight metabolites were identified, and complete assignments of ${ }^{1} \mathrm{H}$ and ${ }^{13} \mathrm{C}$ resonances including many complex coupled spin systems were obtained.
\end{abstract}

urine metabolites, NMR spectroscopy, solid phase extraction, metabonomics/metabolomics

\section{Introduction}

Metabolite analysis has long been an important aspect of biological sciences and the nuclear magnetic resonance (NMR)-based metabonomics have been proven as a powerful technology for measuring the metabolic responses of living systems to internal or external stimu$\mathrm{li}^{[1-5]}$. This is because (1) the changes in gene and protein levels are often manifested into much greater changes in the metabonomes offering a better opportunity to detect such alterations, and (2) the number of metabolites is also conceived smaller than that of genes and proteins. Nevertheless, metabonomics is still under rapid development in both theory and technology aspects $^{[1-13]}$. Conventional metabolite analysis requires complicated sample preparations but often results in information on some limited number of metabolites. The rapid development of analytical technologies makes it possible for metabonomic analysis of a large number of samples containing many metabolites. Amongst many metabonomic detecting techniques, $\mathrm{NMR}^{[9,14-21]}$ and mass spectrometry ${ }^{[22-26]}$ remain the most important.

As one of the most widely used analytical techniques in both chemistry and biosciences, NMR provides information on molecular structure, dynamics and interactions with unbiased detection. For example, ${ }^{1} \mathrm{H}$ NMR spectra show proton signals of all constituents in a complex mixture with the same response coefficients. The position of signals in NMR spectra, described by chemical shift, is directly related to the electron environment of the given atoms and 2D NMR techniques provide direct atomic connectivity ${ }^{[27]}$ in the metabolite molecules, thus structure, whereas the signal intensity is linearly proportional to the quantity of the analytes. Therefore, the NMR spectra can be considered as quantitative "finger-prints" for a metabonome. Due to its non-destructive nature, NMR can be used to analyze the

Received July 2, 2007; accepted August 23, 2007

doi: 10.1007/s11426-008-0031-6

'Corresponding author (email: wjyang@cashq.ac.cn; Huiru.tang@wipm.ac.cn) Supported by the Chinese Academy of Sciences (Grant No: KZCX2-YW-420-21), the National High Technology Research and Development Program of China (Grant No: 2006AA06Z424), and the National Natural Science Foundation of China (Grant Nos: 40590392 and 20575074) 
composition of metabolites under or close to the physiological conditions. With some spectral editing techniques ${ }^{[27]}$, one can also separate signals of metabolites according to their physical properties without separating samples ${ }^{[15,27,28]}$. With high resolution magic-angle spinning NMR and in vivo magnetic resonance techniques, the metabolites in biological tissues can also be analyzed which are exemplified in a number of studies of biological tissues such as the liver ${ }^{[9,19,28-30]}$ and intestine ${ }^{[31,32]}$.

Urine samples are one of the most frequently used biofluids for metabonomics studies, which consist of metabolites including amino acids, hydroxycarboxylic acids, carbohydrates and inorganic salts. The changes of these metabolites can be directly employed to reflect the biochemical changes in a living system. The NMR spectra of urine samples are normally assigned using a catalogue of 2D NMR methods and in situ "spiking" experiments. However, the complexity of urinary composition makes the complete assignments of the urinary spectra difficult with spiking alone or even with the combination of 2D NMR and spiking methods. For example, in situ spiking experiments require the so-called metabolite standards which are not necessarily available all the time. In particular, the standards for unknown metabolites, by default, are not available at all. Consequently, for the time being, only about one-third of detectable urinary metabolites have been assigned unambiguously. In order to improve the spectral assignment, this paper is aimed to provide a different strategy by employing pre-treatment of urine with solid phase extraction techniques to simplify urine samples according to their polarity and enhance the concentration of some minor metabolites together with a catalogue of 2D NMR techniques.

\section{Experimental section}

\subsection{Materials}

C18 solid phase extraction columns (or cartridges) were purchased from IST (International Sorbent Technology, $\mathrm{UK})$ in the format of $0.5 \mathrm{~g}(6 \mathrm{~mL})$ and $2 \mathrm{~g}(12 \mathrm{~mL}$. Eluting solvents were aqueous formate buffer (formic acid and ammonium formate mixture, $\mathrm{pH}=2.8$ ) containing acetonitrile $\left(\mathrm{CH}_{3} \mathrm{CN}\right)$. Formic acid and ammonium formate were purchased from Fisons Scientific U.K. Limited with purity of $98 \%$ and $99.3 \%$, respectively. $\mathrm{CH}_{3} \mathrm{CN}$ was purchased from BDH Laboratory Supplies with purity of $99.9 \% . \mathrm{D}_{2} \mathrm{O}(99.9 \% \mathrm{D})$ was purchased from Goss Scientific Instruments Ltd whilst sodium 3trimethylsilyl-2,2,3,3-tetradeuteropropionate (TSP, 98\%) was from Cambridge Isotope Laboratory Inc. Urine samples from two healthy male adult volunteers (northern Chinese, 36 and 38 years old) were collected once in the morning and afternoon on two separate days respectively without any diet or lifestyle control, and stored at $-40^{\circ} \mathrm{C}$ prior to analysis.

\subsection{Sample pre-treatment and SPE fractionation}

C18 SPE cartridges $(2 \mathrm{~g}, 6 \mathrm{~mL})$ were activated with 24 $\mathrm{mL} \mathrm{CH}_{3} \mathrm{CN}$ with elution rate of $6 \mathrm{~mL} / \mathrm{min}$ followed by conditioning with $25 \mathrm{~mL}$ formate buffer $(0.1 \%, \mathrm{pH}=3)$ containing $2 \% \mathrm{CH}_{3} \mathrm{CN}$ with the eluting rate of $6 \mathrm{~mL} / \mathrm{min}$. Urine samples $(6 \mathrm{~mL})$ were mixed with $0.12 \mathrm{~mL} \mathrm{CH}_{3} \mathrm{CN}$ and their $\mathrm{pH}$ was adjusted to $\mathrm{pH}=3$ with formic acid prior to being loaded onto the SPE cartridge. The column was eluted with $15 \mathrm{~mL}$ formate buffer containing $2 \% \mathrm{CH}_{3} \mathrm{CN}$ to obtain the first fraction (Fraction 1). The column was then eluted with $15 \mathrm{~mL}$ formate buffer containing $15 \% \mathrm{CH}_{3} \mathrm{CN}$ to yield the second fraction (Fraction 2) and with $15 \mathrm{~mL}$ the same buffer containing $35 \% \mathrm{CH}_{3} \mathrm{CN}$ to collect the third fraction (Fraction 3). The cartridge was further eluted with $15 \mathrm{~mL}$ formate buffer containing $50 \% \mathrm{CH}_{3} \mathrm{CN}$ to obtain the fourth fraction (Fraction 4) followed with $20 \mathrm{~mL}$ formate (containing $75 \% \mathrm{CH}_{3} \mathrm{CN}$ ) eluation to obtain the final fraction (Fraction 5). After evaporating $\mathrm{CH}_{3} \mathrm{CN}$ in a fume hood, the fractions were lyophilized and the resultant powers were added with $\mathrm{D}_{2} \mathrm{O}$ followed with certrifugation to retrieve the supernatant for NMR experiments.

\subsection{NMR spectroscopy}

All NMR spectra were recorded on a Bruker AV600 NMR spectrometer equipped with a $5 \mathrm{~mm}$ conventional inverse triple resonance probe at $298 \mathrm{~K}$ and a $3 \mathrm{~mm}$ inverse Cryoprobe $^{\mathrm{TM}}$ at $292 \mathrm{~K}$. For the $5 \mathrm{~mm}$ probe, the sub-fractions were reconstituted to $550 \mu \mathrm{L}$ in a standard $5 \mathrm{~mm}$ NMR tube, whereas they were made up to $150 \mu \mathrm{L}$ sample in an $1.7 \mathrm{~mm}$ capillary NMR tube for the cryoprobe and handled with a Bruker $\mathrm{MATCH}^{\mathrm{TM}}$ device. Both probes were equipped with a shielded gradient coil in $Z$-axis capable of delivering about $50 \mathrm{G} / \mathrm{cm}(1 \mathrm{G}=$ $10^{-4} \mathrm{~T}$ ) pulse gradient. The length of $90^{\circ}$ pulses was adjusted to about $10 \mu$ s unless specifically stated other- 
wise.

One dimensional ${ }^{1} \mathrm{H}$ NMR spectra were acquired using a standard 1D-NOESY pulse sequence with presaturation (NOESYPR1D, RD- $90^{\circ}-t_{1}-90^{\circ}-t_{\mathrm{m}}-90^{\circ}-\mathrm{Aq}$ ), where the recycle delay, $\mathrm{RD}$, was $2 \mathrm{~s}, t_{1}$ was $4 \mu \mathrm{s}$, and mixing time, $t_{\mathrm{m}}$, was $0.1 \mathrm{~s}$. In the case of the first fraction of urine, the $90^{\circ}$ pulse was $13 \mu$ s due to high salt concentration. 64 transients were collected into 32768 data points for each spectrum with a spectral width of 16 ppm unless specified otherwise. Water suppression was achieved with a weak continuous wave irradiation, equivalent to $50 \mathrm{~Hz}$, on the water resonance during both the recycle delay and mixing time. The free induction decays (FIDs) were multiplied by an exponential function with a $0.3 \mathrm{~Hz}$ line-broadening factor prior to Fourier transformation.

Two dimensional (2D) NMR experiments were performed on a $600 \mathrm{MHz}$ spectrometer equipped with a 3 mm cryoprobe. ${ }^{1} \mathrm{H}-{ }^{1} \mathrm{H}$ COSY $2 \mathrm{D}$ NMR spectra were acquired using a gradient selected pulse sequence (RD-90 ${ }^{\circ}-t_{1}-g p 1-90^{\circ}$-gp2- $\left.t_{2}-A q\right)$ in the magnitude mode. Typical parameters include recycle delay of $1.1 \mathrm{~s}$, gradient pulse length of $1.5 \mathrm{~ms}$. The gradient pulses were sine-shaped with the strength of $3 \mathrm{G} / \mathrm{cm}$ and the spectra widths were $10.5 \mathrm{ppm}$ on both dimensions. 256 increments with the 2048 data points in the acquisition dimensions were collected with 40 transients per increment. ${ }^{1} \mathrm{H}-{ }^{1} \mathrm{H}$ TOCSY $2 \mathrm{D}$ NMR spectra were recorded with 2048 data points and 40 scans per increment with 128 increments; spectral width for both dimension was 10.5 ppm. MLEV-17 sequence ${ }^{[33]}$ was employed as spin-locking scheme with mixing time of $90 \mathrm{~ms}$ in the TPPI mode, and the recycle delay was $1.1 \mathrm{~s}$.

${ }^{1} \mathrm{H}_{-}{ }^{13} \mathrm{C}$ HSQC 2D NMR spectra were recorded at 600.22 MHz for ${ }^{1} \mathrm{H}$ and $150.92 \mathrm{MHz}$ for ${ }^{13} \mathrm{C}$ with gradient selection in the echo-antiecho mode. 304 scans were collected into 2048 data points each increment with 11 ppm for ${ }^{1} \mathrm{H}$ and $200 \mathrm{ppm}$ for ${ }^{13} \mathrm{C}$ for 128 increments. The recycle delay was $1.1 \mathrm{~s}$ with GARP as the decoupling scheme. ${ }^{1} \mathrm{H}-{ }^{13} \mathrm{C}$ HMBC 2D NMR spectra were recorded using gradient selection, magnitude mode and optimized for the long-range coupling of $6 \mathrm{~Hz} .128$ increments were recorded with 480 scans and 2048 data points per increment; the spectral width was $11 \mathrm{ppm}$ for ${ }^{1} \mathrm{H}$ and $220 \mathrm{ppm}$ for ${ }^{13} \mathrm{C}$, and the recycle delay was $1.1 \mathrm{~s}$.

All 2D data sets were applied appropriate sine-bell or phase shifted sine-bell functions depending on the phase mode of evolution dimension prior to Fourier transformation into $2048 \times 2048$. Forward linear prediction was employed for the increment dimension to improve resolution for the second dimension.

\section{Results and discussion}

\section{1 ${ }^{1} \mathrm{H}$ NMR spectroscopy of SPE fractions of hu- man urine}

Figure 1 shows the ${ }^{1} \mathrm{H}$ NMR spectra of the five SPE fractions from human urine. It is obvious that the spectra are significantly different for all fractions and signals became weaker as the elution progressed. The first fraction shows the strongest proton signals from the polar metabolites since the highest concentration metabolites are mostly from the polar ones in urine samples. Spectrum of the Fraction 1 is dominated by signals in the $\delta(2.5-4.5)$ region corresponding to polar metabolites, such as amino acids and hydroxycarboxylic acids whereas aromatic signals at $\delta(6.5-8) \mathrm{ppm}$ are barely visible. Fraction 3 appears to be mainly containing fatty acids with resonances at $\delta(0.7-2)$ ppm, whilst Fraction 4 and Fraction 5 only have some weak signals, showing a few metabolites in these fractions. These observations are consistent with the fractionation feature of the reverse- phase chromatographic separation of the urine metabolites and with the fact that urinary metabolites are dominated by relatively polar compounds.

\subsection{D NMR spectroscopy of the urinary SPE frac- tions}

2D NMR techniques provide information on atomic connectivity with improved spectral resolution, assisting metabolite identification unambiguously. Figure 2 shows the examples for the ${ }^{1} \mathrm{H}-{ }^{1} \mathrm{H}$ COSY and TOCSY 2D NMR spectra for Fraction 1 of one of the urine samples providing the proton connectivity, whereas Figure 3 shows ${ }^{1} \mathrm{H}-{ }^{13} \mathrm{C}$ HSQC and HMBC 2D NMR spectra of the same fraction providing information on the $\mathrm{H}-\mathrm{C}$ connectivity and long range atomic connectivity. Figure 4 shows the J-resolved spectra of the fraction providing information about the coupling patterns for each proton signal.

From detailed analysis of these 2D NMR spectra, more than 70 metabolites have been identified with detailed NMR information such as ${ }^{1} \mathrm{H}$ and ${ }^{13} \mathrm{C}$ chemical shifts, ${ }^{1} \mathrm{H}$ coupling patterns, and coupling constants (Figures 5, 6). Compared with "spiking" method, the 

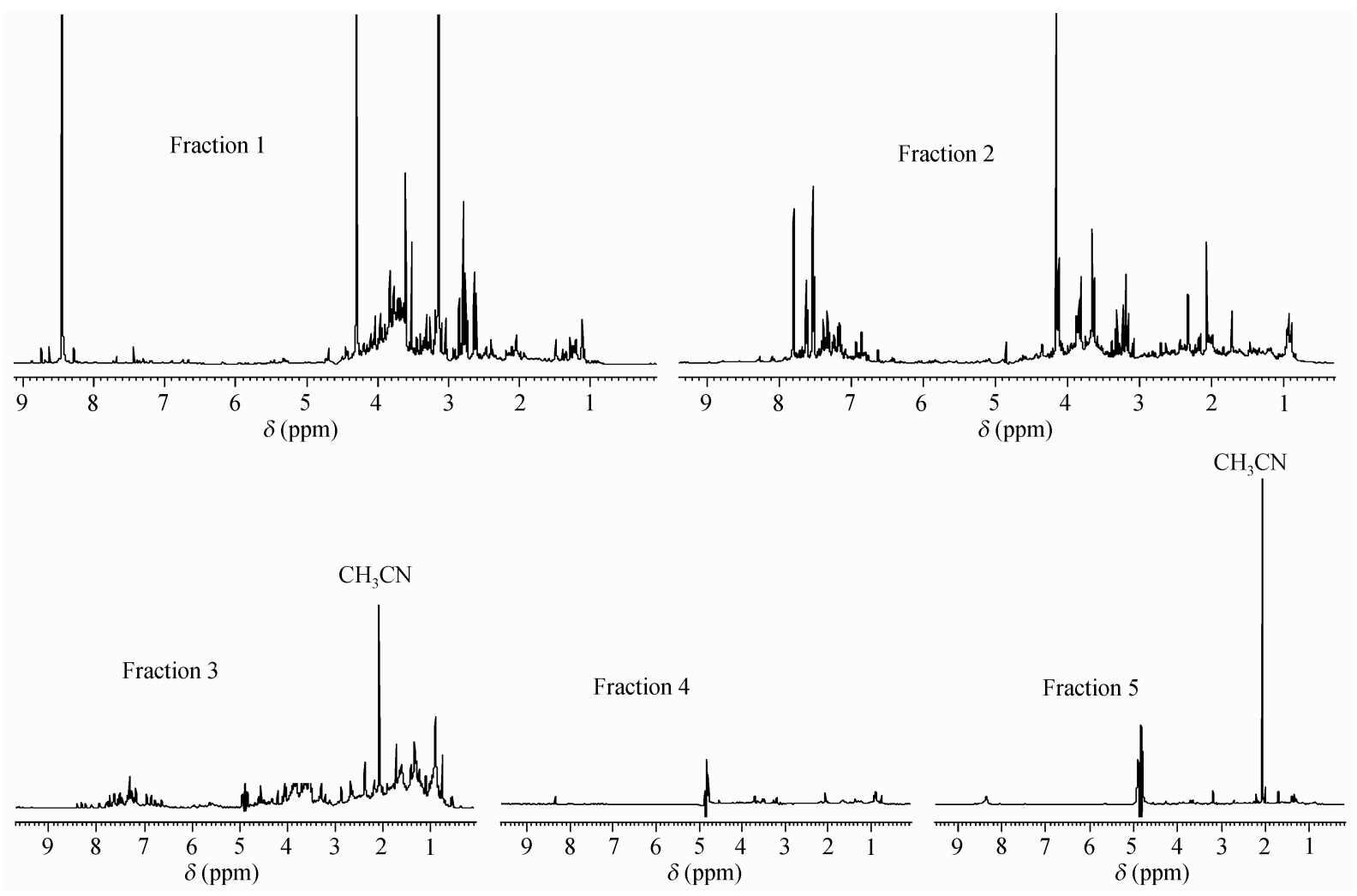

Figure $1 \quad{ }^{1} \mathrm{H}$ NMR spectra of urinary fractions.
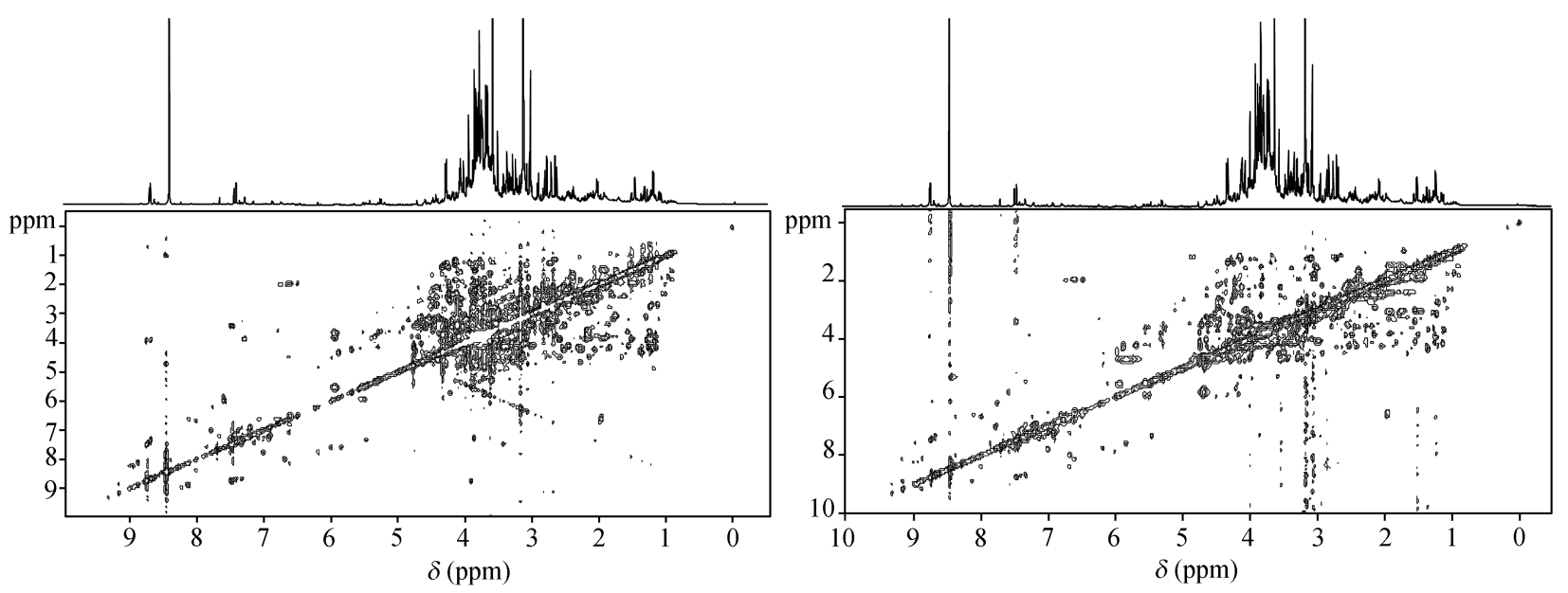

Figure $2{ }^{1} \mathrm{H}-{ }^{1} \mathrm{H}$ COSY and TOCSY (right hand) 2D NMR spectra of Fraction 1.

SPE-NMR methods used here do not require standards, and are relatively simple and potentially useful for detection of some metabolites otherwise not observable.

Amongst these 73 metabolites, 49 of them were detected in Fraction 1, whereas 18 metabolites were assigned from Fraction 2. Only 7 metabolites were assigned from Fraction 3, 4 and 5, which is largely consistent with the fact that most of the urinary metabolites are polar ones. From Fracton 1, most polar amino acids were observed, such as histidine and its methyl derivative, glycine and its dimethyl derivative, alanine and its 3-methylamino derivative. Hydrophobic amino acids such as phenylalanine, tyrosine and valine were not detected. Generally, many amino acids were not widely reported from the urine samples, especially when NMR was used, due to their low concentration. However, the SPE methods used in this study provided a way of concentrating some of the weak metabolites aiding their 


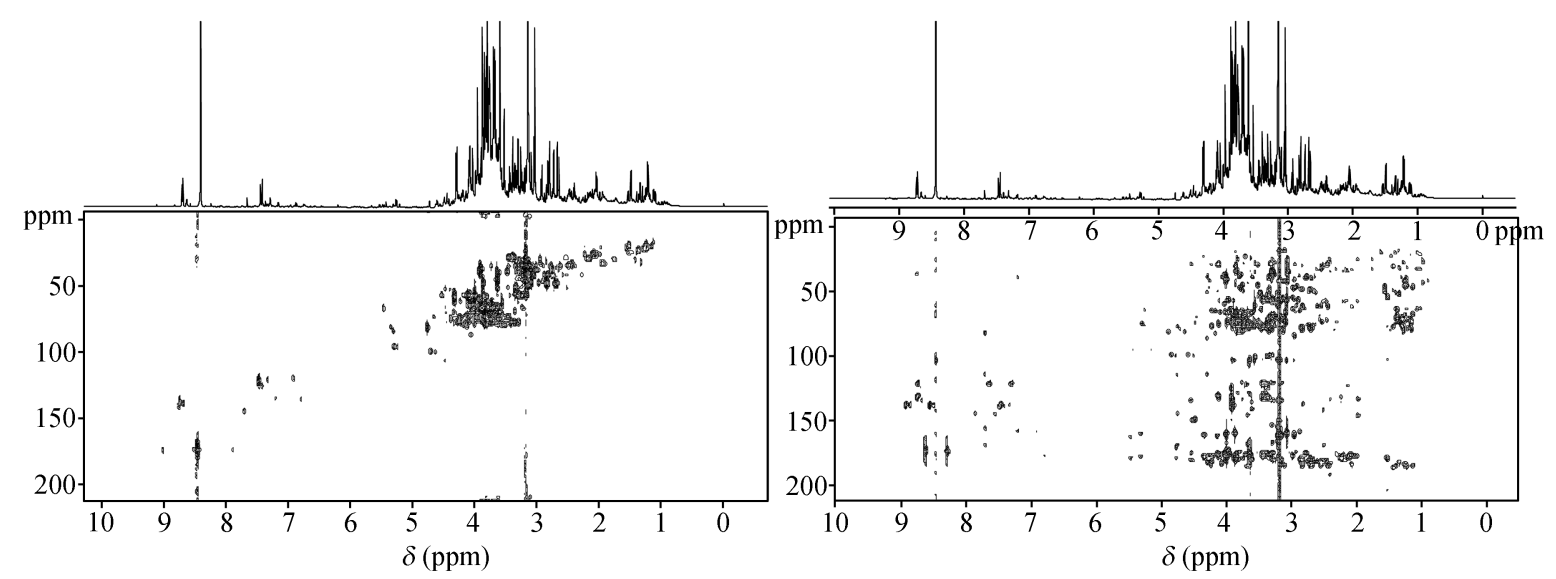

Figure $3 \quad{ }^{1} \mathrm{H}^{13} \mathrm{C}$ HSQC and HMBC (right hand) 2D NMR spectra of Fraction 1.
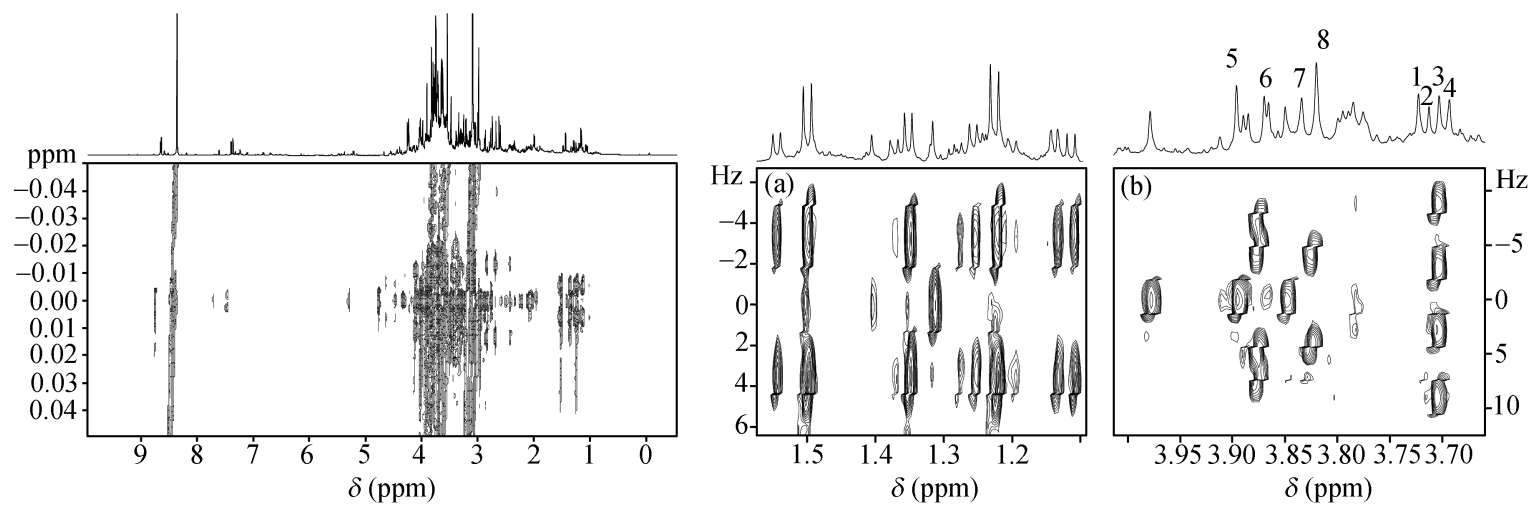

Figure $4 \quad{ }^{1} \mathrm{H}$ J-Resolved 2D NMR spectra of Fraction 1 (regional expansions).

NMR detection. $\beta$-amino-isobutyrate was detected in this urine sample, which is consistent with the fact that this sample was donated from a Northern Chinese. Creatine and creatinine were also observed together with carboxylic acids including citrate, pyruvate, malonate and a derivative of butyrates, which is consistent with the results normally reported from the NMR studies. In addition, basic metabolites, such as trimethylamine and its derivatives trimethylamine oxide and dimethyalmine, were also detected. Small amounts of glucose and mannitol were also detected together with methylnicotinamide and methylnicotinate. In contrast, Fraction 2 contained a number of phenylacetate derivatives, including hippurate, phenylacetate, para-hydroxyhippurate, and 4-hydroxyphenylacetate, which originated from the gut microflora metabolites or co-metabolism between host and gut microbiota. Other metabolites from gut microflora were also detected, such as para-methylphenol ${ }^{[34,35]}$. Tryptophan was also detected in this fraction. Fraction 3 contained 3-(3-methoxy-4-hydroxyphenyl) proprionate and indole-3-acetate ${ }^{[29]}$. It is noteworthy that lactate, which has high polarity and good water solubility, appeared in Fraction 4 but not in the earlier fraction probably owing to its intermolecular hydrogen bonding effects or some protein-binding effects. It is also worth pointing out that all fractions studied here were in acidic condition, and therefore chemical shifts may differ to various extents from that under neutral $\mathrm{pH}^{[36]}$. The most noticeable such examples were histidine and its derivatives, such as 1-methylhistindines, anserine, and 3-methylhistindines (Table 1). This reminds one that when metabonomics studies were carried out, attention had to be paid to the $\mathrm{pH}$ effects on the chemical shifts.

\subsection{Conclusions}

Spectral assignment is fundamentally important for metabonomics studies. SPE fractionation combined with 2D NMR spectroscopic methods is a simple but useful way to identify the metabolites which otherwise may not be able to be detected or unambiguously assigned. Such 


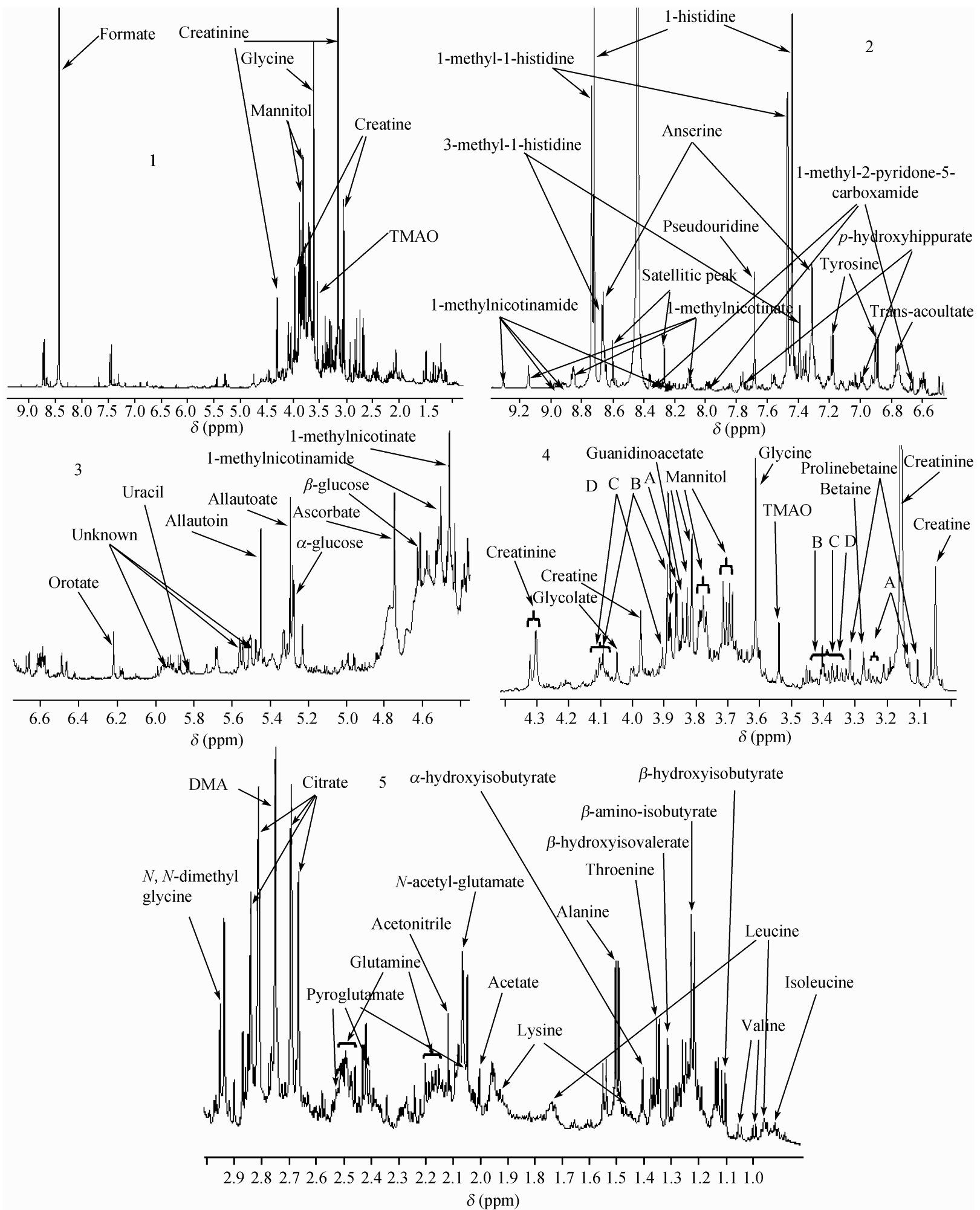

Figure 5 The 1D-H NMR of fraction 1 of SPE. $\delta(0.8-9.5) \mathrm{ppm}(1) ; \delta(6.5-9.4) \mathrm{ppm}(2) ; \delta(4.4-6.5) \mathrm{ppm}(3) ; \delta(3.0-4.4) \mathrm{ppm}(4)(\mathrm{A}$ : anserine, B: 1-methyl- $L$-histidine, C: 3-methyl- $L$-histidine, D: histidine); $\delta(0.9-3.0) \mathrm{ppm}(5)$.

method provides a strategy which is not dependent on the standard "spiking" method. SPE fractionation not only simplified spectral assignment, but also enhanced the detecting sensitivity for some minor metabolites by enhancing their concentration together with the intrinsic sensitivity enhancement with the cryogenic NMR tech- 


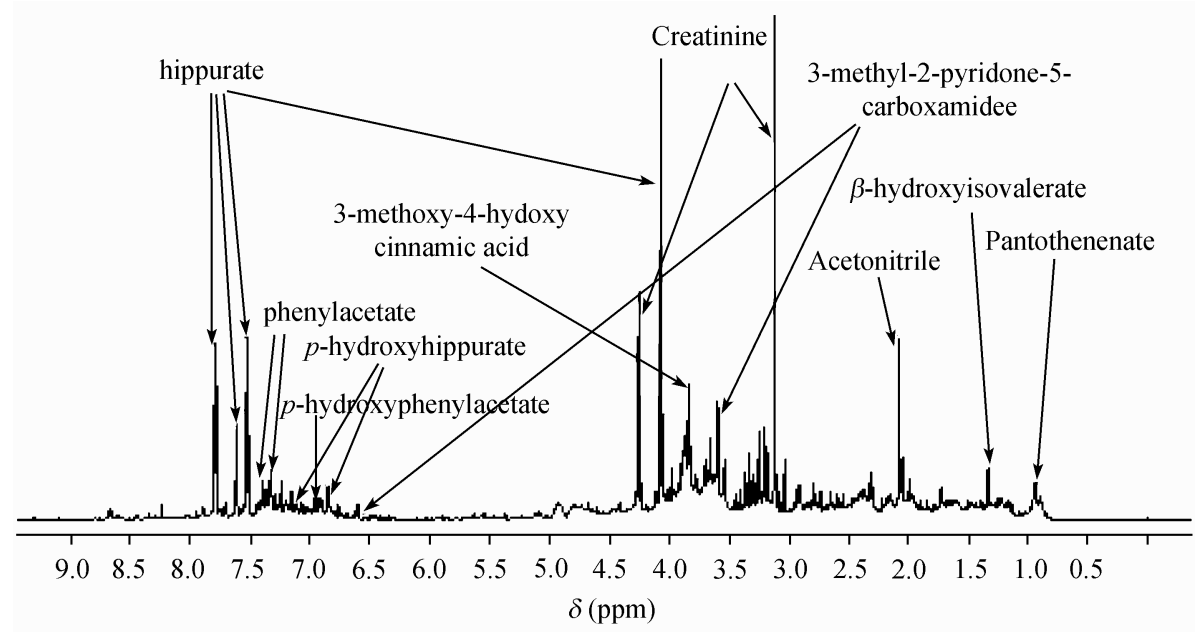

Figure 6 The ${ }^{1} \mathrm{D}-\mathrm{H}$ NMR of fraction 2 of SPE, $\delta(9-0) \mathrm{ppm}$.

Table 1 The $\mathrm{pH}$ effects on the chemical shifts of histidine and its derivatives

\begin{tabular}{|c|c|c|c|c|c|c|}
\hline \multirow{2}{*}{ Metabolites } & Acidic & Neutral & Acidic & Neutral & Acidic & Neutral \\
\hline & \multicolumn{2}{|c|}{ H-2 (ring) } & \multicolumn{2}{|c|}{$\mathrm{H}-4$ (ring) } & \multicolumn{2}{|c|}{ methyl group } \\
\hline Anserine & 8.66 & 7.95 & 7.32 & 6.97 & 3.86 & 3.72 \\
\hline Histidine & 8.72 & 7.83 & 7.44 & 7.08 & - & - \\
\hline 3-methylhistidine & 8.67 & 7.63 & 7.39 & 7.00 & 3.91 & 3.69 \\
\hline 1-methylhistidine & 8.74 & 7.82 & 7.47 & 7.01 & 3.89 & 3.69 \\
\hline
\end{tabular}

nology. Finally, NMR data from more than 70 metabolites obtained from this study will provide useful information for the future metabolite assignment.

1 Nicholson J K, Lindon J C, Holmes E. 'Metabonomics': Understanding the metabolic responses of living systems to pathophysiological stimuli via multivariate statistical analysis of biological NMR spectroscopic data. Xenobiotica, 1999, 29(11): 1181-1189

2 Tang H R, Wang Y L. Metabonomics: A revolution in progress. Prog Biochem Biophys, 2006, 33(5): 401-417

3 Tang H R, Wang Y L. Nutrimetabonomics-metabonomics in food science. In: Magnetic Resonance in Food Science: From Molecules to Man (eds. Farhat I A, Belton P S, and Webb G A). Cambridge: Royal Society of Chemistry, 2007

4 Tang H R, Wang Y L. High Resolution NMR Spectroscopy in human metabolism and metabonomics. In: Modern Magnetic Resonance, London: Springer-Verlag, 2006

5 Holmes E, Tang H R, Wang Y L, Seger C. The assessment of plant metabolite profiles by NMR-based methodologies. Plant Med, 2006, 72(9): $771-785$

6 Smith L M, Maher A D, Cloarec O, Rantalainen M, Tang H R, Elliott P, Stamler J, Lindon J C, Holmes E, Nicholson J K. Statistical correlation and projection methods for improved information recovery from diffusion-edited NMR spectra of biological samples. Anal Chem, 2007, 79(15): 5682-5689

7 Crockford D J, Holmes E, Lindon J C, Plumb R S, Zirah S, Bruce S J, Rainville P, Stumpf C L, Nocholson J K. Statistical heterospectroscopy, an approach to the integrated analysis of NMR and UPLC-MS data sets: Application in metabonomic toxicology studies. Anal Chem,
WJY and HRT are grateful to Prof. Nicholson J K of Imperial College for the use of NMR facilities, especially the cryogenic probe. WJY acknowledges a visiting scholarship from the Chinese Academy of Sciences.

2006, 78(2): $363-371$

8 Rantalainen M, Cloarec O, Beckonert O, Wilson D J, Tonge R, Rowlinson R, Rayner S, NicksonJ, Wilkinson R W, Mills J D, Trygg J, Nicholson J K, Holmes E. Statistically integrated metabonomicproteomic studies on a human prostate cancer xenograft model in mice. J Proteom Res, 2006, 5(10): 2642-2655

9 Yap I K S, Clayton T A, Tang H R, Everett J R, Hanton G, Provost J P, Net J L, Charuel C, Lindon J C, Nicholson J K. An integrated metabonomic approach to describe temporal metabolic disregulation induced in the rat by the model hepatotoxin allyl formate. J Proteom Res, 2006, 5(10): 2675-2684

10 Plumb R S, Johnson K A, Rainville P, Smith I D, Castro-Perez J M, Nicholson J K. UPLC/MSE. A new approach for generating molecular fragment information for biomarker structure elucidation. Rapid Commun Mass Spectr, 2006, 20(13): 1989-1994

11 Crockford D J, Lindon J C, Cloarec O, Plumb R S, Bruce S J, Zirah S, Rainville P, Stumpf C L, Johnson S K, Holmes J E, Nicholson J K. Statistical search space reduction and two-dimensional data display approaches for UPLC-MS in biomarker discovery and pathway analysis. Anal Chem, 2006, 78(13): 4398-4408

12 Holmes E, Cloarec O, Nicholson J K. Probing latent biomarker signatures and in vivo pathway activity in experimental disease states via statistical total correlation spectroscopy (STOCSY) of biofluids: Application to $\mathrm{HgCl} 2$ toxicity. J Proteom Res, 2006, 5(6): 1313-1320

13 Holmes E, Loo R L, Cloarec O, Coen M, Tang H R, Maibaum E, 
Bruce S, Chan Q, Elliottm P, Stamler J, Wilson I D, Lindon J C, Nicholson J K. Detection of urinary drug metabolite (Xenometabolome) signatures in molecular epidemiology studies via statistical total correlation (NMR) spectroscopy. Anal Chem, 2007, (79): $2629-2640$

14 Liu M L, Tang H R, Nicholson J K, Lindon J C. Recovery of underwater resonances by magnetization transferred NMR spectroscopy (RECUR-NMR). J Magn Reson, 2001, 153(1): 133-137

15 Liu M L, Tang H R, Nicholson J K, lindon J C. Use of ${ }^{1} \mathrm{H}$ NMR determined diffusion coefficients to characterize lipoprotein fractions in human blood plasma. Magn Reson Chem, 2002, S83-S88

16 Brindle J T, Antti H, Holmes E, Tranter G, Nicholson J K, Bettell H W L, Clarke S, Schofield P M, McKilligin E, Mosedale D E, Grainger D J. Rapid and noninvasive diagnosis of the presence and severity of coronary heart disease using ${ }^{1} \mathrm{H}-\mathrm{NMR}$-based metabonomics. Nat Med, 2002, 8(12): 1439-1444

17 Athersuch T J, Keun H, Nicholson J K. Quantitative urinalysis of the mercapturic acid conjugates of allyl formate using high resolution NMR spectroscopy. J Pharm Biomed Anal, 2006, 40: 410-416

18 Wang Y L, Holmes E, Tang H R, Lindon J C, Sprenger N, Turini M E, Bergonzelli G, Fay L B, Kochhar S, Nicholson J K. Experimental metabonomic model of dietary variation and stress interactions. J Proteome Res, 2006, 5: 1535-1542

19 Duarte I F, Stanley E G, Holmes E, Lindon J C, Tang H R, Ferdinand R, McKee C G, Nicholson J K, Vilca-melendze H, Heaton N, Murphy G M. Metabolic assessment of human liver transplants from biopsy samples at the donor and recipient stages using high-resolution magic angle spinning ${ }^{1} \mathrm{H}$ NMR spectroscopy. Anal Chem, 2005, 77(17): $5570-5578$

20 Wang Y L, Tang H R, Nicholson J K, Hylands P J, Sampson J, Holmes E. A metabonomic strategy for the detection of the metabolic effects of chamomile (Matricaria recutita L.) ingestion. J Agri Food Chem, 2005, 53(2): 191-196

21 Wang Y L, Hylands P J, Sampson J, Whitcombe I, Stewart C G, Caiger S, Oru I, Holmes E, Nicholson J K, Metabolomic strategy for the classification and quality control of phytomedicine: A case study of chamomile flower (Matricaria recutita L.). Plant Med, 2004, 70(3): $250-255$

22 Plumb R S, Johnson K A, Rainville P, Shockcor J P, Williams R, Granger J H, Wilson I D. The detection of phenotypic differences in the metabolic plasma profile of three strains of Zucker rats at 20 weeks of age using ultra-performance liquid chromatography/orthogonal acceleration time-of-flight mass spectrometry. Rapid Commun Mass Spectr, 2006, 20(19): 2800-2806

23 Wilson I D, Plumb R, Granger J, Major H, Williams R, Lenz E M. HPLC-MS-based methods for the study of metabonomics. J Chromat Anal Technol Biomed Life Sci, 2005, 817(1): 67-76

24 Yin P Y, Zhao X J, Li Q R, Wang J S, Li J H, Xu G W. Metabonomics study of intestinal fistulas based on ultraperformance liquid chromatography coupled with Q-TOF mass spectrometry (UPLC/Q-TOF MS). J Proteom Res, 2006, 5(9): 2135-2143

25 Yang J, Zhao X J, Liu X L, Wang C, Gao P, Wang J S, Li L J, Gu J R,
Yang S L, Xu G W. High performance liquid chromatography-mass spectrometry for metabonomics: Potential biomarkers for acute deterioration of liver function in chronic hepatitis B. J Proteom Res, 2006, 5(3): $554-561$

26 Qiu Y, Su M, Liu Y, Chen M, Gu J, Zhang J, Jia W. Application of ethyl chloroformate derivatization for gas chromatography-mass spectrometry based metabonomic profiling. Anal Chim Acta, 2007, 583(2): 277-283

27 Tang H R, Wang Y L, Nicholson J K, Lindon J C. Use of relaxation-edited one-dimensional and two dimensional nuclear magnetic resonance spectroscopy to improve detection of small metabolites in blood plasma. Anal Biochem, 2004, 325(2): 260-272

28 Wang Y L, Bollard M E, Keun H, Antti H, Beckonert O, Ebbels T M, Lindon J C, Holmes E, Tang H R, Nicholson J K. Spectral editing and pattern recognition methods applied to high-resolution magic-angle spinning ${ }^{1} \mathrm{H}$ nuclear magnetic resonance spectroscopy of liver tissues. Anal Biochem, 2003, 323(1): 26-32

29 Martin F P J, Dumas M E, Wang Y L, Legido-Quigley C, Yap I K S, Tang H R, Murphy Z G M, Cloarec O, Lindon J C, Sprenger N, Fay E L B, Kochlar S, Holmes E, Nicholson J K. A top-down systems biology view of microbiome-mammalian metabolic interactions in a mouse model. Mol Systems Biol, 2007, 3: 112

30 Yang Y X, Li C L, Nie X, Feng X S, Chen W X, Yue Y, Tang H R, Deng F. Metabonomic studies of human hepatocellular carcinoma using high-resolution magic-angle spinning ${ }^{1} \mathrm{H}$ NMR spectroscopy in conjunction with multivariate data analysis. J Proteom Res, 2007, 6: $2605-2614$

31 Wang Y L, Tang H R, Holmes E, Lindon J C, Turini M E, Sprenger N, Bergonzelli G, Fay L B, Kochhar S, Nicholson J K. Biochemical characterization of rat intestine development using high-resolution magic-angle-spinning ${ }^{1} \mathrm{H}$ NMR spectroscopy and multivariate data analysis. J Proteom Res, 2005, 4(4): 1324-1329

32 Wang Y L, Holmes E, Comelli E M, Fotopoulos G, Dorta G, Tang H R, Rantalainen M, Lindon J C, Corthesy I E, Fay L B, Kochhar D, Nicholson J K. Topographical variation in metabolic signatures of human gastrointestinal biopsies revealed by high-resolution magicangle spinning ${ }^{1} \mathrm{H}$ NMR spectroscopy. J Proteom Res, 2007: 6(10): $3944-3951$

33 Bax A, Davis D G, MLEV-17-based two-dimensional homonuclear magnetisation transfer spectroscopy. J Magn Reson, 1985, 65(2): $355-360$

34 Wang Y L, Holmes E, Nicholson J K, Cloarec O, Chollet J, Tanner M, Singer B H, Utzinger J. Metabonomic investigations in mice infected with Schistosoma mansoni: An approach for biomarker identification. Proc Natl Acad Sci 2004, 101(34): 12676- 12681

35 Wang Y L, Utzinger J, Xiao S H, Xue J, Nicholson J K, Marcel T S B $\mathrm{H}$, Holmes E. System level metabolic effects of a Schistosoma japonicum infection in the Syrian hamster. Mol Biochem Parasitol, 2006, 146(1): 1-9

36 Fan T W M, Metabolite profiling by one- and two-dimensional NMR analysis of complex mixtures. Prog NMR Spectr, 1996, 28: 161219 